\title{
Horizontal Nucleate Flow Boiling Heat Transfer Coefficient Measurements and Visual Observations for R12, R134a, and R134a/Ester Lubricant Mixtures
}

Mark A. Kedzierski

Michael P. Kaul

Building and Fire Research Laboratory

Gaithersburg, Maryland 20899

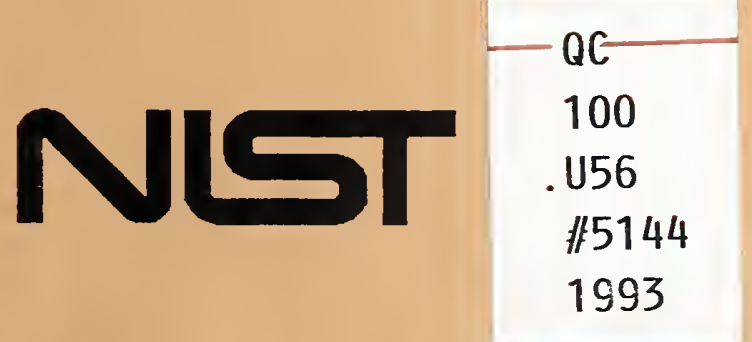

United States Department of Commerce

Technology Administration

National Institute of Standards and Technology 



\section{Horizontal Nucleate Flow Boiling Heat Transfer Coefficient Measurements and Visual Observations for R12, R134a, and R134a/Ester Lubricant Mixtures}

Mark A. Kedzierski

Michael P. Kaul

March 1993

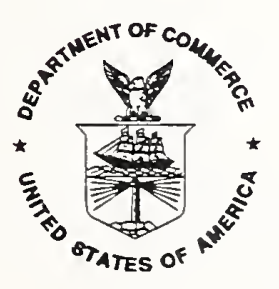

U.S. Department of Commerce

Ronald H. Brown, Secretary

John W. Lyons, Acting Under Secretary for Technology

National Institute of Standards and Technology

Raymond G. Kammer, Acting Director

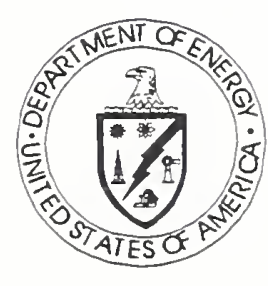

Prepared for:

U.S. Department of Energy

Office of Conservation \&

Renewable Energy

1000 Independence Ave., SW

Washington, DC 20585 



\begin{abstract}
The heat transfer characteristics of horizontal nucleate flow boiling of R12, R134a, and $\mathrm{R} 134 \mathrm{a} /$ Ester Lubricant mixtures were investigated both visually and calorimetrically. The effect of two different ester lubricants on the boiling characteristics of R134a were investigated. The test refrigerant entered a roughened quartz tube test section slightly above the saturated state. Both the heat flux and the Reynolds number were varied in order to investigate their effect on the heat transfer coefficient. The heat transfer increased nearly proportionally with an increase in the heat flux. An increase in the Reynolds number caused a marginal increase in the heat transfer coefficient. Locally measured heat transfer coefficients were taken simultaneously with high speed motion picture images of the boiling process. The motion pictures were used to obtain a descriptive behavior of the boiling which was compared directly to the measured heat transfer coefficients. The rate of bubble production for pure R134a was $38 \%$ greater than that of R12. This is the most likely reason that the R134a heat transfer coefficient was approximately $20 \%$ greater than that of $\mathrm{R} 12$. The addition of lubricant to R134a caused a drastic reduction in the diameter of the bubbles. In fact, for one R134a/lubricant mixture, the bubbles were emitted from the surface as a mist. The addition of the low viscosity lubricant to R134a enhanced the heat transfer of R134a. For Reynolds numbers above 8000, the addition of the high viscosity lubricant degraded the heat transfer as compared to that of the pure component. A mechanistic explanation for the observed R134a/lubricant boiling is provided.
\end{abstract}

Keywords: Building Technology, Boiling, Dichlorodifluoromethane (R12), 1,1,1,2tetrafluoroethane(R134a), heat transfer coefficients, lubricants, visualization 


\section{ACKNOWLEDGEMENTS}

This work was funded jointly by NIST and the U.S. Department of Energy (project no. DEAI01-91CE23808) under Project Manager Terry G. Statt. The authors would like to thank the following personnel of NIST for their constructive criticism of the first draft of the manuscript: Mr. W. Mulroy, Dr. J. Parise, Dr. D. Ripple, Dr. M. Moldover and Mrs. J. Land. The authors would also like to express their appreciation to A. Huffman of Castrol Inc. for providing the Icematic SW 100 which was the proprietary polyol ester test lubricant. Thanks also goes to Dr. T. Dekleva and Ms. A. Savage of ICI for supplying the neopentyle polyol ester (Emkarate 213b) test lubricant. 
TABLE OF CONTENTS

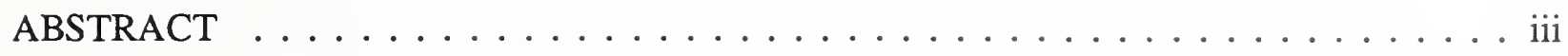

ACKNOWLEDGEMENTS $\ldots \ldots \ldots \ldots \ldots \ldots \ldots \ldots \ldots \ldots$

TABLE OF CONTENTS $\ldots \ldots \ldots \ldots \ldots \ldots \ldots \ldots$

NOMENCLATURE $\ldots \ldots \ldots \ldots \ldots \ldots \ldots \ldots \ldots \ldots \ldots \ldots$

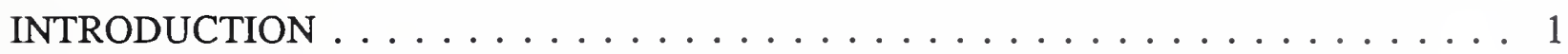

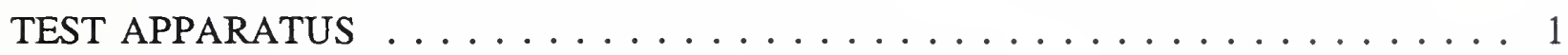

VISUAL TECHNIQUE $\ldots \ldots \ldots \ldots \ldots \ldots \ldots \ldots \ldots \ldots \ldots$

CALORIMETRIC RESULTS . . . . . . . . . . . . . . . . 4

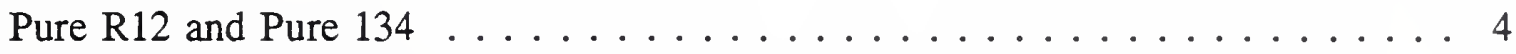

R134a/Polyol Ester Mixture ......................... 5

Correlation of Heat Transfer Coefficient . . . . . . . . . . . . . . . 7

VISUAL RESULTS $\ldots \ldots \ldots \ldots \ldots \ldots \ldots \ldots \ldots \ldots \ldots \ldots \ldots \ldots$

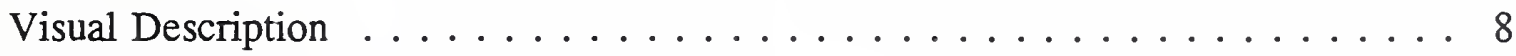

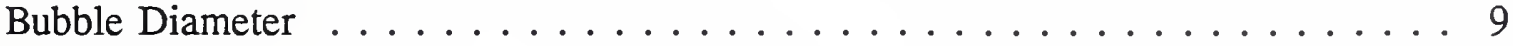

Bubble and Site Densities .......................... 10

MECHANISTIC SPECULATIONS . . . . . . . . . . . . 10

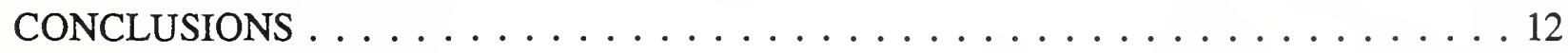

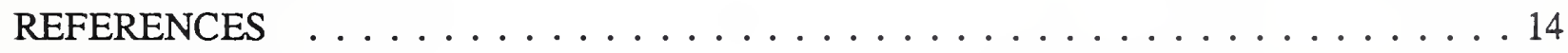

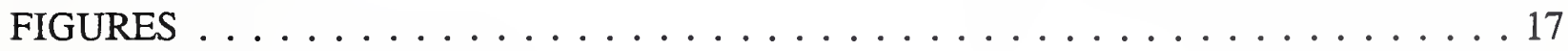


NOMENCLATURE

English Symbols

$c_{\mathrm{p}} \quad$ specific heat $(\mathrm{J} / \mathrm{kg} \cdot \mathrm{K})$

C correlation constant

$D_{d} \quad$ departure diameter of bubble (m)

$D_{i} \quad$ Internal diameter of quartz tube (m)

E boiling constant in eqn. 5

g gravitational acceleration $\left(\mathrm{m} / \mathrm{s}^{2}\right)$

$\mathrm{h}_{2 \phi} \quad$ two-phase heat transfer coefficient $\left(\mathrm{W} / \mathrm{m}^{2} \cdot \mathrm{K}\right)$

$\mathrm{h}_{\mathrm{fg}} \quad$ latent heat of vaporization $(\mathrm{J} / \mathrm{kg})$

$\mathrm{K}_{\mathrm{p}} \quad$ dimensionless pressure, see eqn. 6

$\mathrm{k}$ thermal conductivity $(\mathrm{W} / \mathrm{m} \cdot \mathrm{K})$

m mass flow rate $(\mathrm{kg} / \mathrm{s})$

n site density (sites $/ \mathrm{m}^{2}$ )

$\mathrm{P}$ pressure $(\mathrm{Pa})$

$\mathrm{Pe} \quad$ Peclet number, see eqn. 7

$\mathrm{P}_{\mathrm{c}} \quad$ critical pressure $(\mathrm{Pa})$

$\mathrm{P}_{\mathrm{r}} \quad$ reduced pressure $=\mathrm{P}_{\mathrm{S}} / \mathrm{P}_{\mathrm{c}}$

$\mathrm{P}_{\mathrm{s}} \quad$ saturation pressure $(\mathrm{Pa})$

$\mathrm{q}^{\prime}$ heat flux $\left(\mathrm{W} / \mathrm{m}^{2}\right)$

$\operatorname{Re} \quad$ Reynolds number $=4 \dot{\mathrm{m}} / \mu_{1} \cdot \pi \cdot \mathrm{D}_{\mathrm{i}}$

$\mathrm{R}_{\mathrm{a}}$ mean surface roughness (m)

$R_{p} \quad$ Glättungstiefe or peak-to-mean surface roughness (m)

$\mathrm{R}_{\mathrm{q}} \quad$ rms surface roughness (m)

$\mathrm{T}_{\mathrm{s}} \quad$ saturation temperature $(\mathrm{K})$

$\mathrm{T}_{\text {wi }}$ temperature of the internal tube wall (K)

$W$ mass fraction of lubricant in mixture

\section{Greek symbols}

$\beta \quad$ dynamic contact angle (deg.)

$\Delta \mathrm{T}_{\mathrm{s}} \quad \mathrm{T}_{\mathrm{s}}-\mathrm{T}_{\mathrm{wi}}(\mathrm{K})$

$\mu \quad$ dynamic viscosity $(\mathrm{kg} / \mathrm{m} \cdot \mathrm{s})$

$\nu \quad$ kinematic viscosity $\left(\mathrm{m}^{2} / \mathrm{s}\right)$

$\rho$ density $\left(\mathrm{kg} / \mathrm{m}^{3}\right)$

$\sigma \quad$ surface-tension $(\mathrm{N} / \mathrm{m})$

\section{$\underline{\text { Subscripts }}$}

$\begin{array}{ll}\text { 1 } & \text { liquid } \\ \text { L } & \text { lubricant } \\ \text { m } & \text { mixture } \\ \text { r } & \text { pure refrigerant } \\ \text { S } & \text { solid surface } \\ \text { v } & \text { vapor }\end{array}$




\section{INTRODUCTION}

This paper presents a calorimetric and visual investigation of horizontal nucleate flow boiling of five different fluids: (1) dichlorodifluoromethane (R12), (2) 1,1,1,2-tetrafluoroethane (R134a), (3) R134a/1.7\% proprietary polyol ester lubricant, (4) R134a/0.9\% neopentyle polyol ester lubricant, and (5) R134a/2.3\% neopentyle polyol ester lubricant. The calorimetric aspect of this study concentrates on the measurement of the local two-phase heat transfer coefficient $\left(\mathrm{h}_{2 \phi}\right)$. The visual measurements obtained from high-speed $16 \mathrm{~mm}$ film of the boiling were taken simultaneously with the calorimetric measurements. The bubble diameters $\left(\mathrm{D}_{\mathrm{b}}\right)$, and the bubble density were derived from over 50 high-speed films.

The purpose of this study is to provide a source of heat transfer information for the boiling of R12 and R134a/ester lubricant mixtures. Automotive and supermarket companies have begun to manufacture original air conditioning/refrigeration equipment with R134a as the operating fluid (Bas, 1992 and ACHR News, 1992). The evaporator predominantly utilized by these industries is the in-tube heat exchanger. Naturally, designers of such evaporators require heat transfer coefficients for the horizontal flow boiling of R134a/ester mixtures. Ester lubricants have been chosen by the industry because they are miscible with R134a and do not react as readily with system contaminants as the polyalkylene glycol lubricants do (Corr et al., 1991). Consequently, the effects of two polyol ester lubricants on the boiling characteristics of R134a were examined. The proprietary polyol ester was chosen for study since it has a high viscosity which is typical of mobile air-conditioning lubricants. The kinematic viscosity of this lubricant is nominally $100 \mu \mathrm{m}^{2} / \mathrm{s}$ (500 SUS) at $313.15 \mathrm{~K}$. The lower viscosity lubricant, neopentyle polyol ester, is suitable for stationary refrigeration, which exists in supermarkets. Its kinematic viscosity is $20.5 \mu \mathrm{m}^{2} / \mathrm{s}$ (100 SUS) at $313.15 \mathrm{~K}$.

Only the nucleate flow boiling regime was investigated in this study with the aim of furthering the understanding of the fundamental heat transfer mechanisms responsible for this phenomenon. Strictly speaking, merely a fraction of the heat exchange area of most direct-expansion evaporators resides in the nucleate flow boiling regime. Most of the area of this type of evaporator operates in the convective regime. However, the nucleate fraction of the heat exchanger may be increased due to increased cycle efficiency requirements which may be achieved by lowering the entering vapor quality to the evaporator. Nevertheless, an understanding of the influences of lubricant on R134a nucleate flow boiling may lead to a general understanding of refrigerant/lubricant interaction. A truly generic understanding of the refrigerant/lubricant interaction for nucleate flow boiling may assist in the examination of refrigerant/lubricant interaction for other flow regimes.

\section{TEST APPARATUS}

Following is a discussion of the test apparatus and the accuracies associated with the individual measurements. Unless otherwise stated, all accuracies are estimated for a $99.7 \%$ confidence interval. 
A schematic of the test apparatus is shown in Fig. 1 to illustrate the circulation of refrigerant through the individual components of the rig. A hermetic, oil-free pump was used to deliver a constant flow rate throughout the test rig. The test fluid entered the fluid heater subcooled and exited in a two-phase state at near $1 \%$ vapor quality. The electric heater was used to achieve higher flow qualities entering the test section. After exiting the test section, the fluid entered a liquid reservoir which served to condense the vapor produced by the quartz tube and the fluid heaters and to establish and maintain a steady system pressure. The liquid exiting the condenser was subcooled by approximately $40 \mathrm{~K}$ and entered the mass flow meter. The refrigerant mass flow rate $(\dot{m})$ was measured with a coriolis flow meter with an accuracy of $1-2 \%$ of the measured value. The test loop was completed by returning the liquid to the pump.

The test section consisted of a $9 \mathrm{~mm}$ internal diameter $\left(D_{i}\right)$ quartz tube with a $3 \mathrm{~mm}$ wall thickness. A $0.25 \mathrm{~mm}$ thick, $3 \mathrm{~mm}$ wide brass strip was located along the bottom of the tube with its length aligned with the flow direction. A direct current was passed through the brass strip to produce a range of uniform heat fluxes (q") from 15 to $30 \mathrm{~kW} / \mathrm{m}^{2}$. The quartz tube was enclosed in a safety housing with four flat windows located at horizontal and vertical poles for lighting and filming of the experiment. The space between the housing and the quartz tube was evacuated in order to minimize the heat loss from the heater strip to the surroundings and, thus, promote one-dimensional conduction into the tube. The all-liquid Reynolds numbers based on the diameter of the quartz tube ranged from 0.0 to 9,500 . The accuracy of the Reynolds number was $1.4-2.2 \%$ of the calculated value. The measurements for all fluids were obtained from the same smooth-tube test rig to ensure that observed differences were due to the characteristics of the fluids.

The inside surface of the quartz tube was roughened with a five micron polish to promote boiling. The measured root mean square $(\mathrm{rms})$ roughness $\left(\mathrm{R}_{\mathrm{q}}\right)$, the Glättungstiefe (peak-tomean) roughness $\left(R_{p}\right)$, and the average roughness $\left(R_{a}\right)$ of the interior quartz surface were approximately $0.36 \mu \mathrm{m}, 1 \mu \mathrm{m}$, and $0.3 \mu \mathrm{m}$, respectively. The $\mathrm{R}_{\mathrm{a}}$ measurement is a good indication of the depth of the average cavity. Close examination of the roughness trace reveals inclusions of approximately 1 micron in width. Presumably, the average cavity is approximately 1 micron wide at the mouth and approximately 0.3 microns deep.

Care must be taken in the instrumentation of a quartz test specimen to measure the heat flux accurately. The main concern is determining what portion of the energy generated in the brass heater strip actually gets into the tube. Figure 2 shows the instrumentation of the quartz tube with a heater composite which was used to measure the heat transfer coefficient. The heater composite was made by cementing two thermocouples to the center of opposing sides of a plastic strip of known thermal conductivity. The thermocouple nearest the tube was approximately 0.5 $\mathrm{mm}$ in diameter and flush with the surface of the plastic. The $5 \mathrm{~mm} \times 3 \mathrm{~mm} \times 76 \mathrm{~mm}$ long plastic strip was cemented to a thin $(0.25 \mathrm{~mm})$ brass strip of equal width and length. The entire heater assembly was then cemented to the bottom of the quartz tube. The purpose of the assembly was, first, to direct most of the heat flux into the quartz tube, and, second, to provide for a method to calculate the amount of heat that enters the tube. 
The heat flux incident to the quartz tube $(\mathrm{q} ")$ and the temperature of the inner tube wall $\left(\mathrm{T}_{\mathrm{wi}}\right)$ were determined from a combination of measurement and theory. The two-dimensional conduction within the plastic strip was modeled to determine the amount of energy transferred to the surroundings from the sides and bottom of the insulating strip. The model predicted a linear heat loss with respect to the temperature difference across the plastic. Consequently, the heat loss from the sides and bottom of the plastic was calculated from the measured temperature difference across the plastic. Next, the heat flux flowing into the quartz tube was calculated from the difference between the measured input power to the heater and the heat escaping from the sides of the plastic. The accuracy of the heat flux calculation was estimated to be \pm 1.7 $\mathrm{kW} / \mathrm{m}^{2}$. The estimated accuracy of the inner tube wall temperature $\left(\mathrm{T}_{\mathrm{wi}}\right)$ calculation was \pm 0.2 $\mathrm{K}$. The $\mathrm{T}_{\mathrm{wi}}$ was extrapolated from the measured temperature of the outer brass strip, using the calculated heat flux and a radial conduction model.

The two-phase heat transfer coefficient $\left(\mathrm{h}_{2 \phi}\right)$ was calculated from:

$$
h_{2 \phi}=\frac{q^{\prime \prime}}{T_{w i}-T_{s}}
$$

where the saturation temperature $\left(\mathrm{T}_{\mathrm{s}}\right)$ was determined from the measured pressure to within 0.8 $\mathrm{K}$. The accuracy of the heat transfer coefficient measurement for most of the data was estimated to be $\pm 10 \%$ of the measured value.

The lubricant mass fraction (W) was calculated, using a modification of the procedure given in ASHRAE Standard 41.1-84 (ASHRAE 1984). The lubricant mass fraction is the ratio of mass of the lubricant to the total mass of the lubricant and refrigerant in the mixture. The results of three $30-60 \mathrm{~g}$ samples were averaged. The refrigerant was evaporated from the lubricant by means of a 48 hour evacuation. The mass fraction measurement was estimated to be accurate to within 0.0005 in mass fraction.

\section{VISUAL TECHNIQUE}

A high-speed $16 \mathrm{~mm}$ camera with a macro lens was used to film the boiling process simultaneously with the heat transfer measurements. All films were color and taken at approximately 6000 frames per second. The film speed was calculated with the aid of timing marks on the film to within $1.3 \%$ of the measured value. All flow qualities were near $1 \%$. The temperature of the fluid entering the quartz tube that was measured with a thermocouple always agreed within $\pm 1 \mathrm{~K}$ of the saturation temperature obtained from the corresponding measured pressure. The flow pattern from a typical pure refrigerant test is presented in Fig. 3. The liquid entering the quartz tube was free of bubbles with the exception of the large plug of vapor that traveled along the top of the tube.

The bubble density and a representative average bubble diameter were measured to within an estimated accuracy of $\pm 3 \%$ of the measurement and $\pm 0.1 \mathrm{~mm}$, respectively. The contact 
angle, the site density, and the bubble frequency could not be measured due to the congested bubble activity at the heated surface. One bubble at the surface could not easily be isolated for study. The bubble density was obtained by counting the number of bubbles within the liquid core for the arbitrary area shown in Fig. 3. Coalesced bubbles were included in the calculation of the average bubble diameter and bubble density. This is unavoidable since an unobstructed view of the bubbles was not possible at the heated surface.

\section{CALORIMETRIC RESULTS}

\section{$\underline{\text { Pure R12 and Pure 134a }}$}

The two-phase heat transfer coefficients of five different fluids were investigated: (1) R12, (2) R134a, (3) R134a/1.7\% proprietary polyol ester mixture, (4) R134a/0.9\% neopentyle polyol ester mixture, and (5) R134a/2.3\% neopentyle polyol ester mixture. All measurements were taken at the same reduced pressure of 0.13 and a flow quality of near $1 \%$. Heat transfer data were taken for Reynolds numbers varying from nearly 0.0 to 9500 at three different heat fluxes $\left(15,20\right.$, and $\left.30 \mathrm{~kW} / \mathrm{m}^{2}\right)$. Figures 4 through 7 are plots of the horizontal two-phase heat transfer coefficient versus the Reynolds number for the three different heat fluxes. Each figure includes the data of R134a so that a comparison between R134a and R134a/lubricant mixtures and R12 and its replacement refrigerant can be readily made.

Figure 4 compares the heat transfer coefficients of R12 to its ozone-safe replacement R134a. The heat transfer coefficient of R134a is on average $20 \%$ greater than that of R12 for an equal heat flux and Reynolds number. Similarly, Takamatsu et al. (1991) showed that the local flow boiling heat transfer coefficient for R134a was on average $25 \%$ greater than that of R12. Most likely, all of their data was in the convective regime. Consequently, this comparison may not be strictly valid since the data presented here is in the nucleate regime. Be that as it may, of all the data examined in the literature, the experimental conditions of the Takamatsu et al. (1991) data were the most similar to those of this study.

The heat transfer coefficient increases nearly linearly with respect to Reynolds number for both fluids. The data for each heat flux for each fluid are nearly parallel to one another, indicating that the rate of increase in $h_{t p}$ with respect to $R e$ is independent of the incident heat flux. Also, notice that the Reynolds number has approximately the same effect on the heat transfer of R12 as it does on R134a. For example, the two-phase heat transfer coefficient of R12 and R134a increases by an average of approximately $310 \mathrm{~W} / \mathrm{m}^{2} \cdot \mathrm{K}$ for an increase in Re from 0 to 9500 .

In general, the heat flux has a much greater effect on the heat transfer coefficient than the Reynolds number. For example, a $33 \%$ increase in the heat flux from 15 to $20 \mathrm{~kW} / \mathrm{m}^{2}$ corresponds to an average increase in the heat transfer coefficient of approximately $20 \%$ for both $\mathrm{R} 12$ and R134a. Likewise, a $50 \%$ increase in the heat flux from 20 to $30 \mathrm{~kW} / \mathrm{m}^{2}$ corresponds to an average increase in the heat transfer coefficient of R12 and R134a by approximately $37 \%$. Clearly, this boiling phenomenon is strongly dependent upon the heat flux. 


\section{$\underline{\text { R134a/Polyol Ester Mixture }}$}

It was assumed that the change in the boiling point of R134a due to the addition of the lubricant was negligible. This assumption is justified by two arguments. First, Stephan (1963) has reported that the boiling point of R12 increases by less than $0.3 \mathrm{~K}$ with an addition of $10 \%$ oil by weight. The lubricant mass fractions measured here were below $3 \%$ by weight which should cause a comparatively small change in the boiling point. Second, no change in the agreement between the measured saturation temperature and the saturation temperature obtained from the measured pressure was observed with the addition of lubricant to the R134a.

The properties of the refrigerant/lubricant mixture were evaluated at the saturation temperature of the pure refrigerant. The liquid density of the lubricant $\left(\rho_{\mathrm{L}}\right)$ and the kinematic viscosity of the lubricant $\left(\nu_{\mathrm{L}}\right)$ were fitted to limited data (Castrol (1991) and ICI (1991)) as a function of temperature in kelvins. The coefficients of the fits for each lubricant are provided in table 1. The densities of the lubricants in kilograms per cubic meter were fitted to the form:

$$
\rho_{L}=C_{0}+C_{1} T_{s}+C_{2} T_{s}^{2}
$$

The kinematic viscosities of the ester lubricants in square meters per second were fitted to the form:

$$
v_{L}=C_{3} \exp \frac{C_{4}}{T_{s}}
$$

The following ideal mixing rule was used to approximate the dynamic viscosity of the refrigerant/lubricant mixture:

$$
\mu_{m}=\exp \left\{W \ln \mu_{L}+(1-W) \ln \mu_{r}\right\}
$$

The surface-tension between the liquid lubricant and air/lubricant vapor $\left(\sigma_{\mathrm{lv}}\right)$ was calculated from the rise height in a $1.2 \mathrm{~mm}$ bore capillary tube. The surface-tension of the proprietary ester was found to be approximately $0.024 \mathrm{~N} / \mathrm{m}$ at $298 \mathrm{~K}$. The surface-tension of the neopentyle polyol ester was found to be approximately $0.026 \mathrm{~N} / \mathrm{m}$ at $298 \mathrm{~K}$. The surface-tension of R134a was obtained from Chae et al. (1990). The surface-tension of R12 was obtained from the International Institute of Refrigeration (1981).

Figure 5 compares the measured two-phase heat transfer coefficient of pure R134a to a mixture of R134a and 0.9 weight percent of neopentyle polyol ester. The heat transfer coefficient is plotted versus the liquid Reynolds number. Two aspects of the comparative heat transfer are immediately evident from the figure. First, the addition of $0.9 \%$ lubricant to pure R134a 
enhances the heat transfer for all heat transfer conditions. Overall, the heat transfer coefficient of the R134a/0.9\% mixture, averaged for all Reynolds numbers and heat fluxes, is $13 \%$ greater than the overall averaged heat transfer coefficient for pure R134a. Second, the addition of the lubricant to R134a has caused the heat transfer, for the highest heat flux condition, to be more responsive to an increase in the Reynolds number. For example, the heat transfer coefficient for the R134a/0.9\% neopentyle polyol ester mixture at the zero Reynolds number condition is greater than that for the pure component by approximately $200 \mathrm{~W} / \mathrm{m}^{2} \cdot \mathrm{K}$. By contrast, the enhancement at a Reynolds number of 9,500 is over twice as large as that at the zero Reynolds number condition; it is approximately $470 \mathrm{~W} / \mathrm{m}^{2} \cdot \mathrm{K}$.

Figure 6 compares the measured two-phase heat transfer coefficient of pure R134a to a mixture of R134a/2.3\% weight percent of neopentyle polyol ester. The heat transfer coefficient of the R134a/2.3\% ester mixture can be examined in terms of: (1) its relative magnitude compared to the pure component, and (2) the influence of the Reynolds number upon it. Examination of the first point above reveals that the heat transfer coefficient of the R134a/2.3\% ester mixture, averaged over all heat transfer conditions, is $15 \%$ greater than that for pure R134a. This is slightly greater than the enhancement associated with the $0.9 \%$ lubricant mass fraction fluid. A study of the second point above indicates that the rate of increase for the R134a/2.3\% alkylbenzene mixture is consistent with the trend exhibited by the fluid with the $0.9 \%$ lubricant mass fraction. For example, at the zero Reynolds number condition and $\mathrm{q}^{\prime \prime}=30 \mathrm{~kW} / \mathrm{m}^{2}$, the heat transfer coefficient of the R134a/2.3\% ester mixture is greater than that of pure R134a by approximately $230 \mathrm{~W} / \mathrm{m}^{2} \cdot \mathrm{K}$. The enhancement approximately doubles to $550 \mathrm{~W} / \mathrm{m}^{2} \cdot \mathrm{K}$ at a Reynolds number of 9,500 and $\mathrm{q}^{\prime \prime}=30 \mathrm{~kW} / \mathrm{m}^{2}$.

Figure 7 compares the measured two-phase heat transfer coefficient of pure R134a to a mixture of R134a and $1.7 \%$ of the proprietary polyol ester. In contrast with the data of the $\mathrm{R} 134 \mathrm{a} /$ neopentyle polyol ester mixture, the R134a/proprietary polyol ester mixture exhibits a heat transfer degradation with respect to the pure fluid at the higher Reynolds numbers. For instance, the greatest heat transfer degradation is at a Reynolds number of 9,500 where the heat transfer coefficient for the $\mathrm{R} 134 \mathrm{a} / 1.7 \%$ ester mixture is from $3 \%$ to $8 \%$ below that of pure $\mathrm{R} 134 \mathrm{a}$. The heat transfer coefficient for the R134a/1.7\% ester mixture averaged for all conditions is approximately $4 \%$ greater than that of the pure R134a.

The enhancement of the heat transfer coefficient of the R134a/neopentyle polyol ester mixture relative to that of pure R134a increased for an increase in the heat flux. Conversely, the enhancement of the heat transfer of the $\mathrm{R} 134 \mathrm{a}$ /proprietary polyol ester mixture relative to pure R134a decreased for an increase in the heat flux. In fact, the heat transfer coefficient for the $\mathrm{R} 134 \mathrm{a}$ /proprietary polyol ester mixture was an average of 3\% below that of pure R134a for the highest heat flux condition $\left(\mathrm{q}^{\prime \prime}=30 \mathrm{~kW} / \mathrm{m}^{2}\right)$. Moreover, in a similar study of nucleate flow boiling of R123/alkylbenzene mixtures, Kedzierski (1992) shows an enhancement relative to pure R134a which is essentially independent of the heat flux.

Overall, the more viscous R134a/lubricant does not "boil as well" as the less viscous R134a/lubricant. Both ester lubricants were completely miscible at the temperatures for which 
the tests were taken. The only significant difference in the transport properties of the lubricants is the liquid viscosity (Castrol, 1991 and ICI, 1991). So, the relatively small enhancement of the $\mathrm{R} 134 \mathrm{a}$ /proprietary ester mixture over pure $\mathrm{R} 134 \mathrm{a}$ as compared to that of the $\mathrm{R} 134 \mathrm{a} /$ neopentyle polyol ester may be primarily due the higher viscosity of the proprietary ester.

\section{Correlation of Heat Transfer Coefficient}

It is difficult to find a heat transfer correlation that applies strictly to horizontal nucleate flow boiling. One candidate correlation form might be a superposition model. Historically, these correlations are generated from a statistical fit of many flow boiling data sources from many different metal tubes. Typically, the effect of surface roughness is not included in the correlation of a superposition model. Yet, as Corty and Foust (1955) have shown, pool boiling strongly depends upon the surface finish. Therefore, rather than comparing the present data with a superposition model for flow boiling, the present data for a zero Reynolds number are compared to three different pool boiling correlations which account for surface roughness effects.

Agreement between the measured heat transfer coefficients and two of the correlations was not acceptable. On average, the heat transfer coefficient for R12 and R134a obtained from Cooper's equation (1984) was overpredicted by approximately $200 \%$. Similarly, poor agreement was achieved with Stephan's and Abdelsalam's (1980) pool boiling equation for refrigerants with the correction for surface roughness.

Good agreement was achieved between the measured heat transfer coefficient at $\operatorname{Re}=0$ and the correlation with the Borishanskii-Minchenko equation (Borishanskii et al., 1969):

$$
h_{2 \phi}=\frac{E K_{p}^{0.7 P e^{0.7} k_{I}}}{\sqrt{\frac{\sigma}{g\left(\rho_{I}-\rho_{V}\right)}}}
$$

where $\mathrm{K}_{\mathrm{p}}$ is the dimensionless pressure:

$$
K_{p}=\frac{P_{s}}{\sqrt{g \sigma\left(\rho_{I}-\rho_{V}\right)}}
$$

and the Peclet number $(\mathrm{Pe})$ is:

$$
P e=\frac{q^{\prime \prime} \rho_{I} c_{p_{I}}}{h_{f g} \rho_{V} k_{I}} \sqrt{\frac{\sigma}{g\left(\rho_{I}-\rho_{V}\right)}}
$$

Equation 5 and the measured heat transfer coefficients for R12 and R134a at Re $=0$ agreed to 
within $\pm 10 \%$ when the dimensionless boiling constant $E$ was set equal to $3.5 \times 10^{-4}$. Rice and Calus (1972) correlated the pool boiling data from an electroplated chromium surface of Cichelli and Bonilla (1945) to the Borishanskii-Minchenko equation with the constant $E=3.92 \times 10^{-4}$. Although roughness values for this surface were not given, a typical $R_{a}$ roughness for an electroplated surface is approximately $0.8 \mu \mathrm{m}$ (Baumeister, 1978). If the constant for Cichelli and Bonilla's data were used to predict the present R12 and R134a data, the data would agree within $20 \%$ of the prediction. However, this value of $\mathrm{E}$ may be inappropriate for the quartz tube since the roughness of the chromium surface is probably greater than that of the quartz tube. Consequently, the value of $E=3.5 \times 10^{-4}$ for the quartz tube seems to be consistent with Cichelli and Bonilla's data since one would expect that the value of $E$ for the quartz tube would be smaller than that for the chromium surface.

As Rice and Calus (1972) have noted, the boiling constant E may not rely entirely upon the properties of the heat transfer surface. Supporting evidence for this is that Kedzierski (1992) obtained a different boiling constant $\left(E=2.5 \times 10^{-4}\right)$ for the same surface which was used in this study for R11 and R123. Although the dimensionless pressure $K_{p}$ is intended to account for the effects of pressure on heat transfer coefficient, one of the significant differences between the R11/R123 data set and the present data set is the reduced pressure. Most likely, the boiling constant is a function of more than just the properties of the heat transfer surface.

\section{VISUAL RESULTS}

\section{Visual Description}

Figure 3 is a descriptive sketch of the observed nucleate flow boiling for pure R12 and pure R134a. For the pure refrigerant, the bubbles are closely packed and cover the entire heated surface. Some of the bubbles slide along the surface under the influence of the motion of the liquid. Some bubbles detach directly from the wall; others form a pile, coalesce, and escape from the top layer of bubbles. The R12 bubbles at the heated surface were larger than those of the R134a bubbles, making it easier to observe individual R12 bubbles. The tiny, closely packed $\mathrm{R} 134 \mathrm{a}$ bubbles resembled a thin film of vapor on the heat surface.

Figures 8 through 10 illustrate the observed mechanism of bubble generation for the R134a/lubricant mixtures. Dense patches of micro bubbles covered approximately $60 \%$ of the heated surface. Between these clouds were regions on the heated surface where no bubble were generated. Above the cloud, mists of bubbles coalesce into larger bubbles and drift into the core of the liquid. The bubbles coalesce into larger bubbles as they travel farther from the heated surface. As Fig. 8 shows, the R134a/0.9\% neopentyle polyol ester coalesced bubbles were the largest of the R134a/lubricant mixtures. The diameter of these bubbles averaged over all heat transfer conditions was $0.3 \mathrm{~mm}$. As illustrated in Fig. 9., a doubling of the lubricant mass fraction caused the size of the coalesced bubble to diminish and their population to increase. The diameter of the R134a/2.3\% neopentyle polyol ester coalesced bubbles averaged over all heat transfer conditions was $0.2 \mathrm{~mm}$. Figure 10 demonstrates that the $\mathrm{R} 134 \mathrm{a} / 1.7 \%$ proprietary polyol ester lubricant had the smallest coalesced bubbles of all the R134a/lubricant mixtures. 
A continuous mist of bubbles extended from the heated surface to the bottom of the liquid-vapor interface of the vapor plug. Consistent with the previous mixtures, the density of the mist appeared to increase with increasing distance from the wall, suggesting that bubbles were becoming larger as they moved away from the wall.

Following is a more detailed analysis of the bubble diameters and bubble density of the pure refrigerants. The bubble pattern for the pure refrigerants is depicted in Fig. 3. It was not possible to calculate the bubble density for the R134a/lubricant mixtures. Therefore, calculations for the bubble densities for only the pure refrigerants are given.

\section{Bubble Diameter}

The average diameter of the R12 and the R134a bubbles was approximately $0.4 \mathrm{~mm}$ and 0.5 $\mathrm{mm}$, respectively. The average diameter of the $\mathrm{R} 134 \mathrm{a} / 0.9 \%$ neopentyle polyol ester and the $\mathrm{R} 134 \mathrm{a} / 2.3 \%$ neopentyle polyol ester mixtures was approximately $0.3 \mathrm{~mm}$ and $0.2 \mathrm{~mm}$, respectively. The diameter of the bubbles for the $\mathrm{R} 134 \mathrm{a} / 1.7 \%$ proprietary polyol ester lubricant was surmised to be no larger than $10 \mu \mathrm{m}$ in diameter.

Fritz (1935) utilized the work of Bashforth and Adams (1883) to calculate the maximum volume of a spherical vapor bubble as a function of Laplace's constant and the contact angle $\beta$ (in degrees) with respect to the solid surface. Fritz's solution is presented in graphical and tabular form. The tabulated solution can be fitter to the following familiar equation for the departure diameter attributed to Fritz:

$$
D_{d}=0.0204 \beta \sqrt{\frac{\sigma}{g\left(\rho_{1}-\rho_{v}\right)}}
$$

For the pure refrigerants, acceptable agreement between the measured bubble diameter and that predicted by the Fritz equation was achieved. An average between the contact angle for pure refrigerants given by Stephan and Abdelsalam (1980) and that given by Kedzierski (1992) is 34 . When this contact angle and the fluid properties are substituted into eqn. 8 , the agreement between the equation and the measured bubble diameter for R134a is within $26 \%$. Equation 8 overestimates the bubble diameter for R 12 by approximately $58 \%$.

The Fritz equation predicts a $17 \%$ increase in the bubble diameter due to the addition of lubricant which is contrary to the observed decrease in the bubble diameter associated with the addition of lubricant to the refrigerant. As a result, it overpredicts the measured bubble diameter for the R123/0.55\% alkylbenzene and the R123/2\% alkylbenzene mixtures by $82 \%$ and $265 \%$, respectively. A contact angle of $40^{\circ}$ was used in the Fritz equation as an attempt to account for the influence of the lubricant (Kedzierski, 1992). 
The bubble density averaged over all heat transfer conditions for the pure refrigerants R12 and R134a is $140 \mathrm{~cm}^{-2}$ and $190 \mathrm{~cm}^{-2}$, respectively. Estimates for the bubble density of the $\mathrm{R} 134 \mathrm{a} /$ neopentyle polyol ester mixtures indicate that the bubble density substantially increases with increasing lubricant mass fraction. Specifically, the bubble density for the R134a/0.9\% neopentyle polyol ester and the R134a/2.3\% neopentyle polyol ester mixture is $500 \mathrm{~cm}^{-2}$ and $2000 \mathrm{~cm}^{-2}$, respectively.

As shown in Fig. 3, the bubbles are closely packed on the surface of the heater. If the average diameter of the bubble $\left(D_{d}\right)$ on the heater surface is known, the site density (n) may be approximated for a packed configuration from:

$$
n=\frac{1}{D_{d}^{2}}
$$

The R12 bubbles at the wall appeared to be approximately the same size as those in the liquid core. By contrast, the R134a bubbles at the heated surface were much smaller than those in the liquid core. An estimate of the size of the R134a bubbles at the wall is not ventured beyond stating that they were smaller than the R12 bubbles at the wall. Since the R134a bubbles are packed and smaller than the R12 bubble, the site density for R134a should be greater than that of R12. The site density for R12 estimated from eqn. 9 is about $600 \mathrm{sites} / \mathrm{cm}^{2}$. It is surmised that the site density of the R134a/lubricant mixtures would be much greater than that for either pure refrigerants since the size of the bubble at the heated surface is significantly smaller than that for the pure refrigerants.

\section{MECHANISTIC SPECULATIONS}

Three deciding parameters for boiling performance are: (1) the individual bubble frequencies, (2) the site densities and, (3) the bubble size. Although we were unable to measure the bubble frequencies, this parameter may not vary much for a particular surface and reduced pressure. For example, Kedzierski (1992) has shown that rather than the bubble frequency the site density and the bubble size were the most important determinants for the heat transfer of nucleate flow boiling of R11, R123 and R123/lubricant mixtures. Accordingly, the visual data is examined in terms of only the site density and the bubble diameter.

In all probability, the heat transfer enhancement of the R134a/neopentyle polyol ester mixture, as compared to that of pure R134a, was a consequence of its enhanced site density and its similar bubble size. Even though the site density of the R134a/proprietary polyol ester mixture was also enhanced, this enhancement was comparatively marginal, since the size of the bubble was substantially reduced. Since the only substantial difference between the two lubricants is the viscosity, the relatively high viscosity of the lubricant may contribute to the extremely small size of the bubble. 
Worsoe-Schmidt (1960) and Manwell and Bergles (1990) have conjectured that the improved heat transfer associated with refrigerant/lubricant mixtures is due to increased wall wetting. Their argument is applied to the stratified flow regime of horizontal flow boiling where the top of the tube is in direct contact with the vapor. The heat transfer is comparatively ineffective where the vapor contacts the tube. Any device that pulls the liquid along the tube wall and into the vapor region would substantially increase the effectiveness of the heat transfer. A rise in the surface-tension of the liquid would accomplish this. Since the surface-tension of lubricants is typically greater than that of refrigerants, refrigerant/lubricant mixtures exhibit greater surface-tension than pure refrigerants. Consequently, the higher surface-tension exhibited by refrigerant/lubricant mixtures results in a greater active heat transfer area by inducing the liquid to climb farther up the wall of the tube.

Presumably, some mechanism, other than wall wetting, is responsible for enhancing nucleate flow boiling of refrigerant/lubricant mixtures. The Worsoe-Schmidt argument applies only to tubes that are heated around the entire circumference. For the tests here, only a $3 \mathrm{~mm}$ wide strip along the bottom of the tube is heated. Consequently, the active heat transfer region is fixed by the constant area of the strip heater. Therefore, the heat transfer enhancement is not due to the mechanism described by Worsoe-Schmidt (1960).

The enhancement mechanism of nucleate flow boiling associated with the addition of lubricant is speculated in the following. The main premise is that the boiling no longer occurs directly on the heated surface. Instead, the boiling occurs from a three-dimensional lubricant-rich surface located on the solid heated surface. Figures 8 through 10 illustrate that the lubricant-rich regions appear as clouds of micro-bubbles. Presumably, the clouds act like porous surfaces in providing many active nucleation sites. Evidence for a porous-like characteristic is that the site density is substantially greater for boiling from clouds than for boiling directly from the heated surface. Thick clouds, like those exhibited by the R134a/neopentyle polyol ester mixtures, produce fewer but larger bubbles than the thin clouds of the R134a/proprietary polyol ester mixture. Correspondingly, the enhancement associated with the R134a/neopentyle polyol ester (low viscosity lubricant) mixtures is greater than that of the R134a/proprietary polyol ester (high viscosity lubricant) mixture.

If the above argument is to be accepted, it must first be acknowledged that a miscible lubricant can be locally immiscible. This can occur if the lubricant is drawn out of solution by the coupled influences of refrigerant evaporation and the lubricant's strong affinity for the solid surface. The strength of the lubricant's affinity for a solid surface is demonstrated by the fact that, even after a surface has been thoroughly cleaned after boiling refrigerant/lubricant mixtures, enough lubricant adheres to the surface such that the pure refrigerant boiling performance cannot be repeated. The lubricant can be drawn out of solution since it is not removed from the heated surface via evaporation. In other words, a refrigerant/lubricant liquid mixture travels to the heated wall and only the refrigerant leaves by evaporation. The refrigerant evaporates and increases the concentration of the lubricant at the wall. The lubricant concentration at the heated surface is established by a balance between the deposition and removal of the lubricant. In summary, preferential evaporation of the refrigerant, along with 
the strong affinity between the lubricant and the surface, results in lubricant-rich regions on the heated surface.

Micro-bubbles are a consequence of the small, attractive forces between the bubble and the lubricant-rich surface which are proportional to: $\sigma_{l v} \sin \beta$. The surface-tension between the liquid and the lubricant-rich layer $\left(\sigma_{1 \mathrm{~L}}\right)$ determines the magnitude of this force by establishing the magnitude of the contact angle $(\beta)$. This can be demonstrated with the use of the Young and Dupré equation (Adamson, 1967) which is a lateral force balance on a bubble attached to a surface:

$$
\beta=\arccos \left(\frac{\sigma_{v s}-\sigma_{1 s}}{\sigma_{1 v}}\right)
$$

The surface tension between a refrigerant/lubricant mixture and a solid surface $\left(\sigma_{\mathrm{ls}}\right)$ is much greater than that between a refrigerant/lubricant mixture and the lubricant $\left(\sigma_{1 \mathrm{~L}}\right)$. In fact, for a perfectly miscible lubricant, the surface-tension between the refrigerant and lubricant is nonexistent. The contact angle for a bubble on a lubricant, rather than a solid surface, can be estimated by substituting the value of $\sigma_{1 \mathrm{~L}}$ for the value of $\sigma_{\mathrm{ls}}$. The resulting contact angle is much smaller than that for a bubble attached directly to a solid surface. Consequently, the forces which hold the bubble to the wall are much less for the refrigerant/lubricant mixture than they are for the pure refrigerant. As a result, a bubble on a lubricant-rich layer is released from that surface before it can grow to a respectable size.

\section{CONCLUSIONS}

Bubble formation during horizontal flow boiling of R12, R134a, and two R134a/polyol ester mixtures was investigated both visually and calorimetrically. The two-phase heat transfer coefficient of five different fluids were investigated: (1) R12, (2) R134a, (3) R134a and 1.7\% of a proprietary polyol ester, (4) R134a and $0.9 \%$ neopentyle polyol ester, and (5) R134a and $2.3 \%$ neopentyle polyol ester. The neopentyle was a low viscosity lubricant $\left(\nu=20.5 \mu \mathrm{m}^{2} / \mathrm{s}\right)$, while the proprietary lubricant had a high viscosity $\left(\nu=100 \mu \mathrm{m}^{2} / \mathrm{s}\right)$. Good agreement was achieved between the measured heat transfer coefficients for R12 and R134a and the Borishanskii-Minchenko equation.

For both R12 and R134a, an increase in either the heat flux or the Reynolds number increases the heat transfer coefficient. The heat flux has a much larger effect on the heat transfer coefficient than the Reynolds number. An increase in the heat flux caused nearly an equal percentage increase in the heat transfer coefficient. The addition of the low viscosity lubricant to the R134a increased the sensitivity of the heat transfer coefficient to an increase in the Reynolds number at the highest heat flux.

The relative magnitudes of the nucleate flow boiling heat transfer coefficient were compared to that of R134a. For Reynolds numbers below 9,500, the heat transfer coefficient of R134a was 
on average $20 \%$ greater than that of R12 for equal heat flux and Reynolds number. The addition of the low viscosity lubricant to pure R134a enhances the heat transfer over the pure R134a for all heat transfer conditions. By contrast, addition of the high viscosity lubricant caused a degradation in the heat transfer coefficient for low Reynolds numbers as compared to pure R134a.

Visual observations of the bubble density and the bubble size were used to explain the heat transfer trends. For example, the pure R134a benefitted from a $38 \%$ greater rate of bubble production over that of pure R12 to attain its superior heat transfer performance. The addition of a low viscosity lubricant to R134a enhanced the heat transfer performance of pure R134a by increasing the site density while maintaining a similar bubble size. The addition of a high viscosity lubricant to R134a resulted in a smaller enhancement of the heat transfer coefficient over pure R134a. This may have resulted from the canceling effects of a drastic reduction in the diameter of the bubbles and a significant increase in the site density. The R134a/lubricant mixture appeared to boil from lubricant-rich clouds on the surface of the heater. The clouds acted like porous surfaces in creating many tiny bubbles. 


\section{REFERENCES}

Adamson, A. W., 1967, Physical Chemistry of Surfaces, Interscience Publ., New York, 2nd Ed., p. 353.

Air Conditioning, Heating and Refrigeration News, 1992, April 27, p. 20.

ASHRAE, 1984, ASHRAE Handbook-1984 Systems, Atlanta: American Society of Heating, Refrigeration and Air-Conditioning, Inc., p. 29.14.

Bas, E., 1992, "Detroit Carmakers Laying CFC-Free Groundwork," Air Conditioning, Heating and Refrigeration News, August 17, p. 10.

Bashforth, F., and Adams, J., 1883, Capillary Action, Cambridge, England.

Baumeister, T., Avallone, E. A., and Baumeister III, T., 1978, Marks' Standard Handbook for Mechanical Engineers, 8th ed., McGraw-Hill, New York.

Borishanskii, V. M., Bobrovich, G. I., and Minchenko, F. P., 1969, "Heat Transfer from a Tube to Water and to Enthanol in Nucleate Pool Boiling," Symposium on Problems of Heat Transfer and Hydraulics of Two-Phase Media, Ed. S. S. Kutateladze, Pergamon Press, London, pp. 85-106.

Castrol, 1991, Technical Data Sheet on Castrol Auto.

Chae, H., B., Schmidt, J. W., and Moldover, M. R., 1990, "Surface Tension of Refrigerants R123 and R134a," J. of Chem. \& Eng. Data, Vol. 35, No. 1, pp. 6-8.

Cichelli, M. T., and Bonilla, C. F., 1945, Trans. AIChE, Vol. 41, pp. 755-787.

Cooper, M. G., 1984, "Saturation Nucleate Pool Boiling-A Simple Correlation, " Proc. 1st U.K. National Conf. on Heat Transfer, Vol. 2, pp. 785-793.

Corr, S., Goodwin, J., Gregson, R. D., Halse, A., and Lindley, A. A., 1991, "Retrofitting Mobile Air-Conditioning Systems with HFC-134a," Proceedings of Int. CFC and Halon Alternative Conference, Baltimore, December, pp. 553-562.

Corty, C., and Foust, A. S., 1955, "Surface Variables in Nucleate Boiling," Chem. Eng. Prog. Symp., Vol. 51, No. 16, pp. 1-12.

Fritz, W., 1935, "Berechnung des Maximalvolumens von Dampfblasen," Physik. Zeitschr., Vol 36, pp. 379-384.

ICI, 1991, "'Emkarate' RL Refrigeration Lubricants," Technical Bulletin CP/C69E/991/2C. 
International Institute of Refrigeration, 1981, Thermodynamic and Physical Properties of R12, Paris.

Kedzierski, M. A., 1992, "Simultaneous Visual and Calorimetric Measurements of R11, R123, and R123/Alkylbenzene Nucleate Flow Boiling," NISTIR 4948, U.S. Department of Commerce, Washington.

Manwell, S. P. and Bergles, A. E., 1990, "Gas-Liquid Flow Patterns in Refrigerant-Oil Mixtures," ASHRAE Transactions, Vol. 96, Part 2, pp. 456-464.

Rice, P. and Calus, W. F., 1972, "Pool Boiling-Single Component Liquids," Chemical Engineering Science, Vol. 27, No. 9, pp. 1677-1687.

Stephan, K., 1963, "Influence of Oil on Heat Transfer of Boiling Refrigerant 12 and Refrigerant 22," XI International Congress of Refrigeration.

Stephan, K., and Abdelsalam, M., 1980, "Heat Transfer Correlations for Natural Convection Boiling," Int. J. Heat Mass Transfer, Vol. 23, pp. 73-87.

Takamatsu, H., Momoki, S., and Fujii, T., 1991, "A Comparison of Evaporation Heat Transfer Coefficients and Pressure Drop in a Horizontal Smooth Tube for HFC134a and CFC12," Proceedings of the XVIII ${ }^{\text {th }}$ International Congress of Refrigeration, Montreal, Vol. II, pp. 444448.

Worsoe-Schmidt, P., 1960, "Some Characteristics of Flow Pattern and Heat Transfer of Freon12 Evaporating in Horizontal Tubes," The J. of Refrigeration, March/April, pp. 40-44. 
Table 1 Constants for property eqns. 2 and 3

\begin{tabular}{|c|c|c|}
\hline $\begin{array}{c}\text { constants } \\
\text { for fits }\end{array}$ & $\begin{array}{c}\text { proprietary } \\
\text { polyol ester }\end{array}$ & $\begin{array}{c}\text { neopentyle polyol } \\
\text { ester }\end{array}$ \\
\hline $\mathrm{C}_{0}$ & $1.023 \times 10^{3}$ & $1.019 \times 10^{3}$ \\
\hline $\mathrm{C}_{0}$ & $1.994 \times 10^{-1}$ & $1.994 \times 10^{-1}$ \\
\hline $\mathrm{C}_{2}$ & $-1.318 \times 10^{-3}$ & $-1.318 \times 10^{-3}$ \\
\hline $\mathrm{C}_{3}$ & $1.364 \times 10^{-10}$ & $9.252 \times 10^{-11}$ \\
\hline $\mathrm{C}_{4}$ & $4.229 \times 10^{3}$ & $3.985 \times 10^{3}$ \\
\hline
\end{tabular}




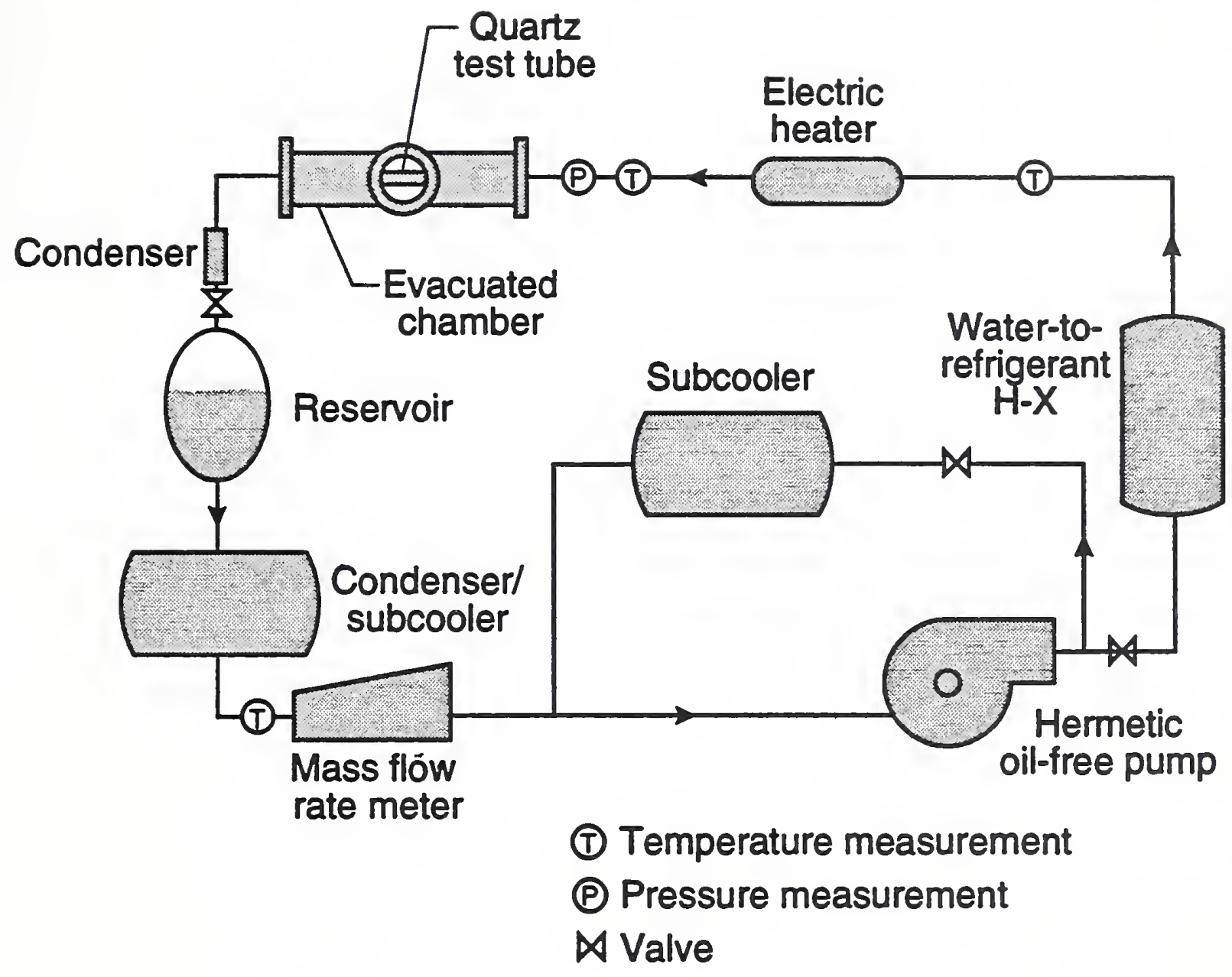

Fig. 1 Schematic of test apparatus 


\section{Fluid, $T_{s}$}

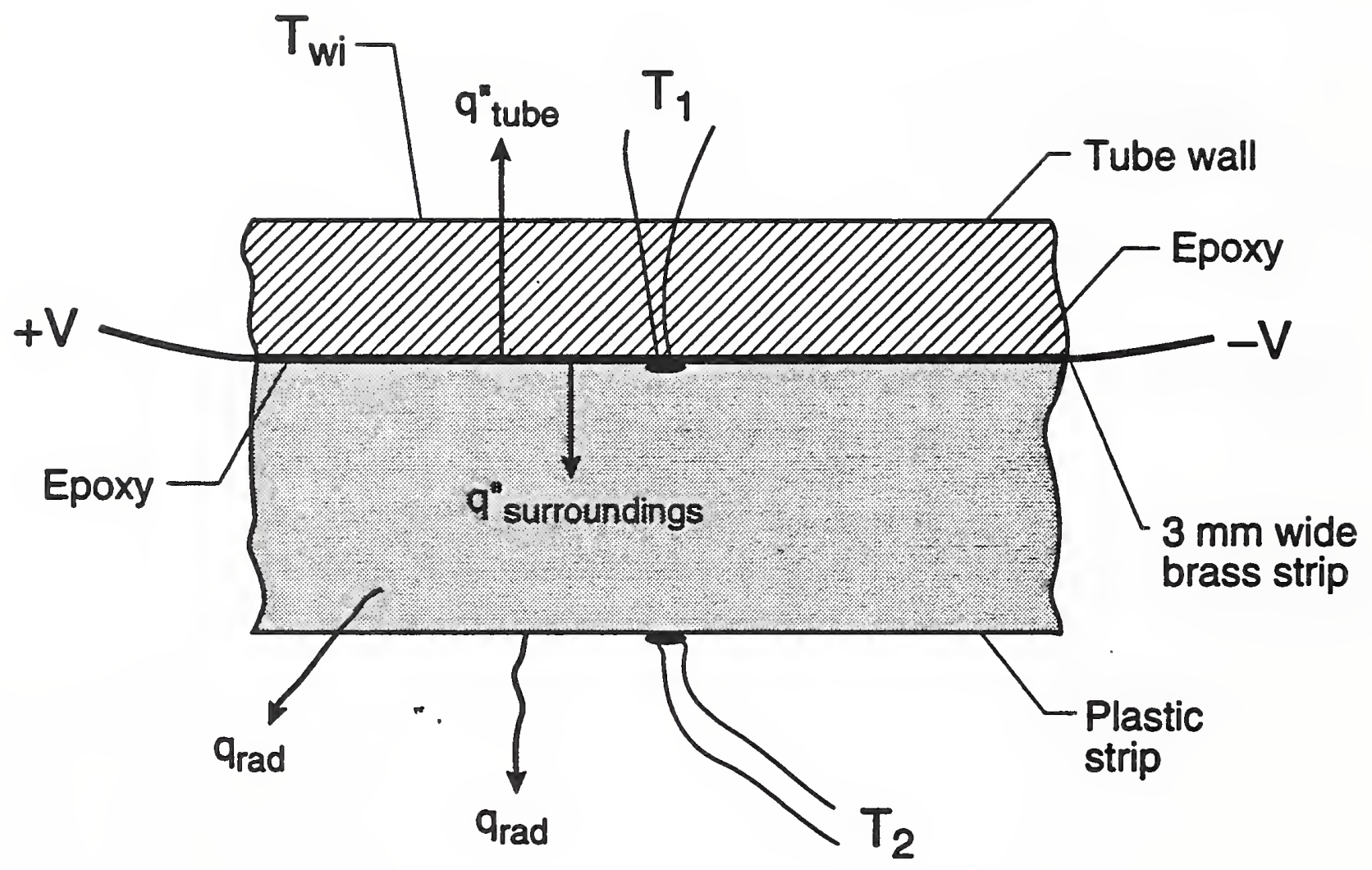

Fig. 2 Schematic of heater composite 


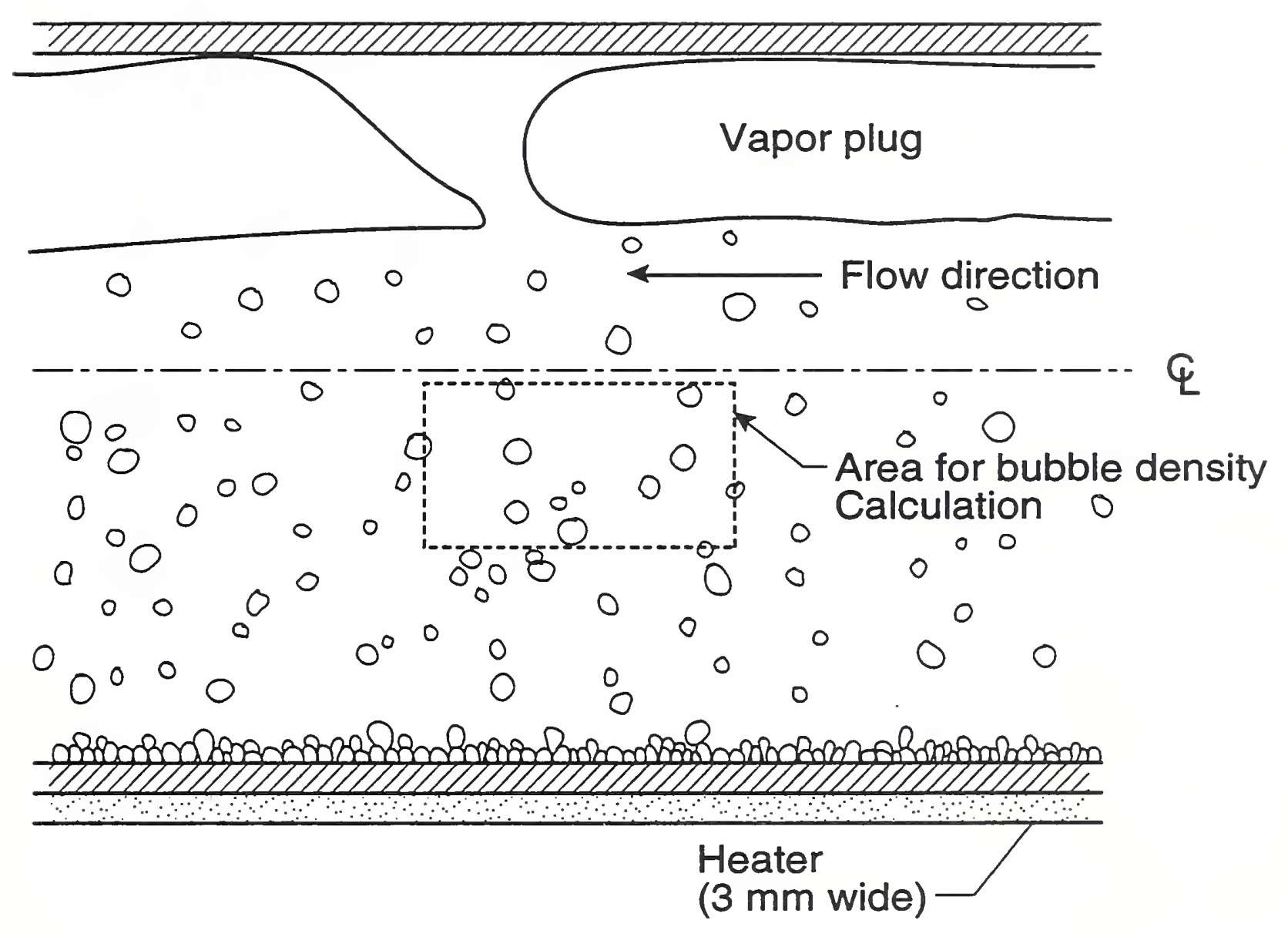

Fig. 3 Typical flow pattern for pure refrigerant nucleate flow boiling 


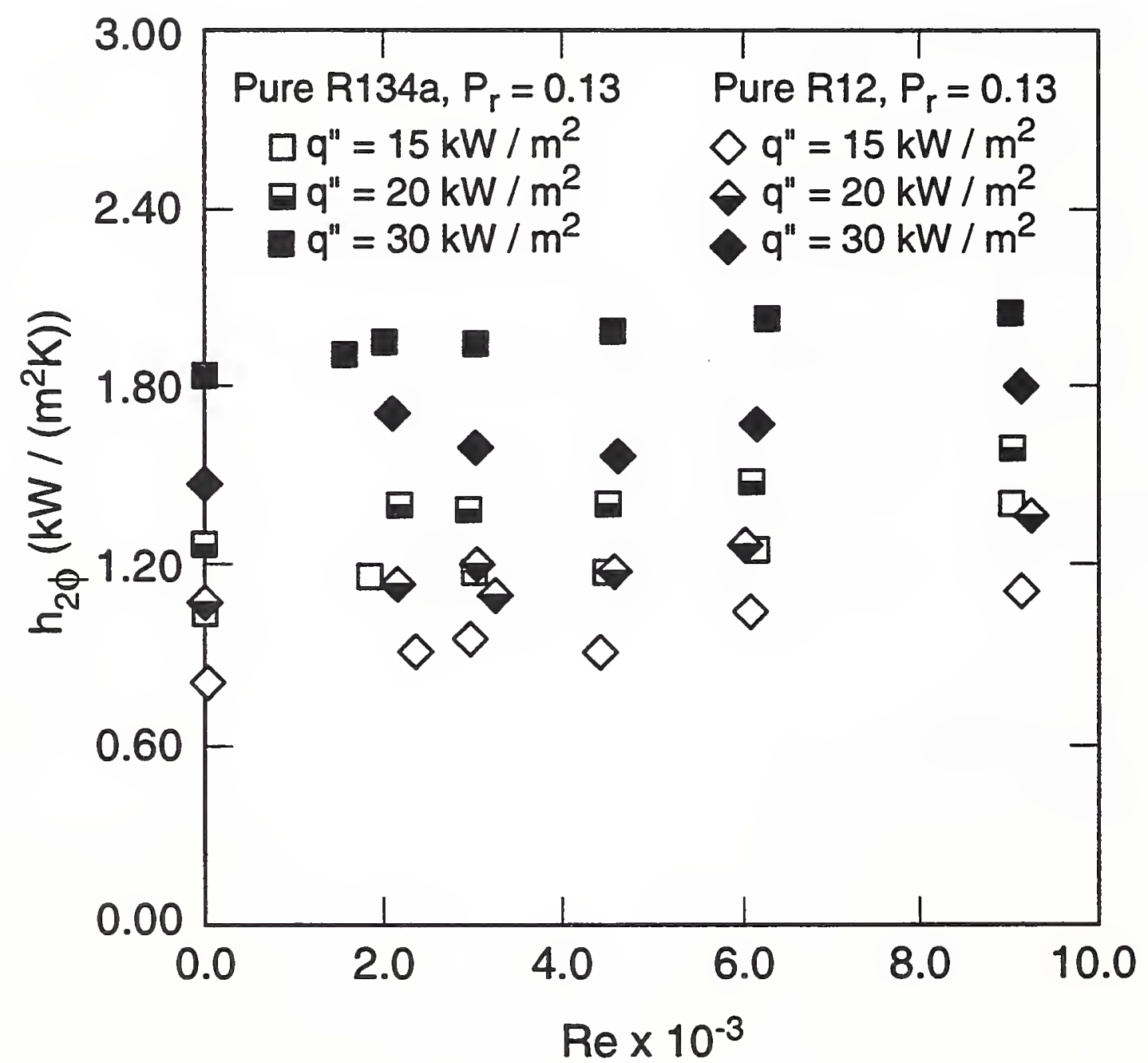

Fig. 4 Two-phase heat transfer coefficient measurements for pure $R 12$ and pure $R 134 a$ at $P_{T}=$ 0.13 


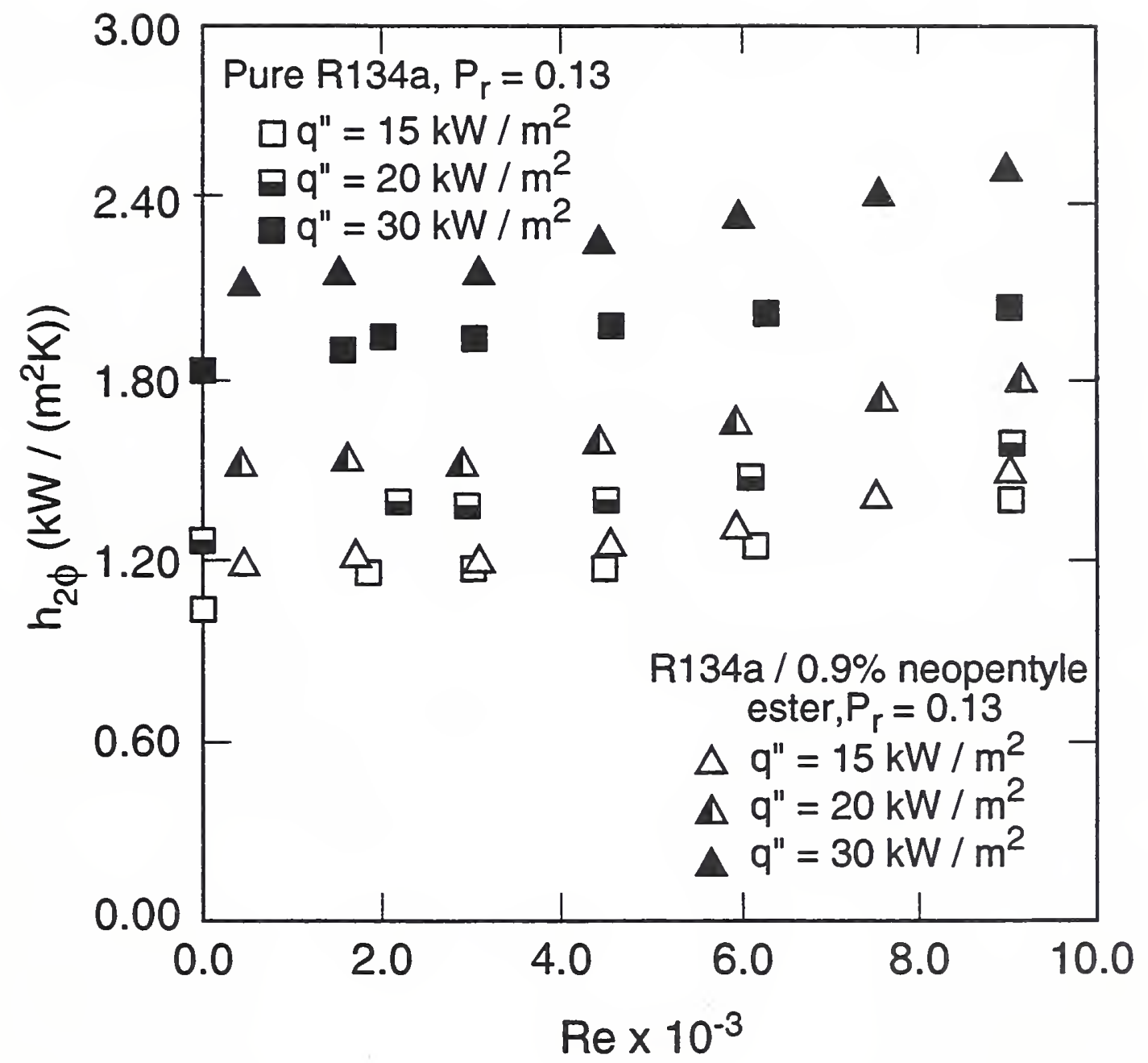

Fig. 5 Two-phase heat transfer coefficient measurements for R134a/ $0.9 \%$ neopentyle polyol ester mixture and pure $\mathrm{R} 134 \mathrm{a}$ at $\mathrm{P}_{\mathrm{r}}=0.13$ 


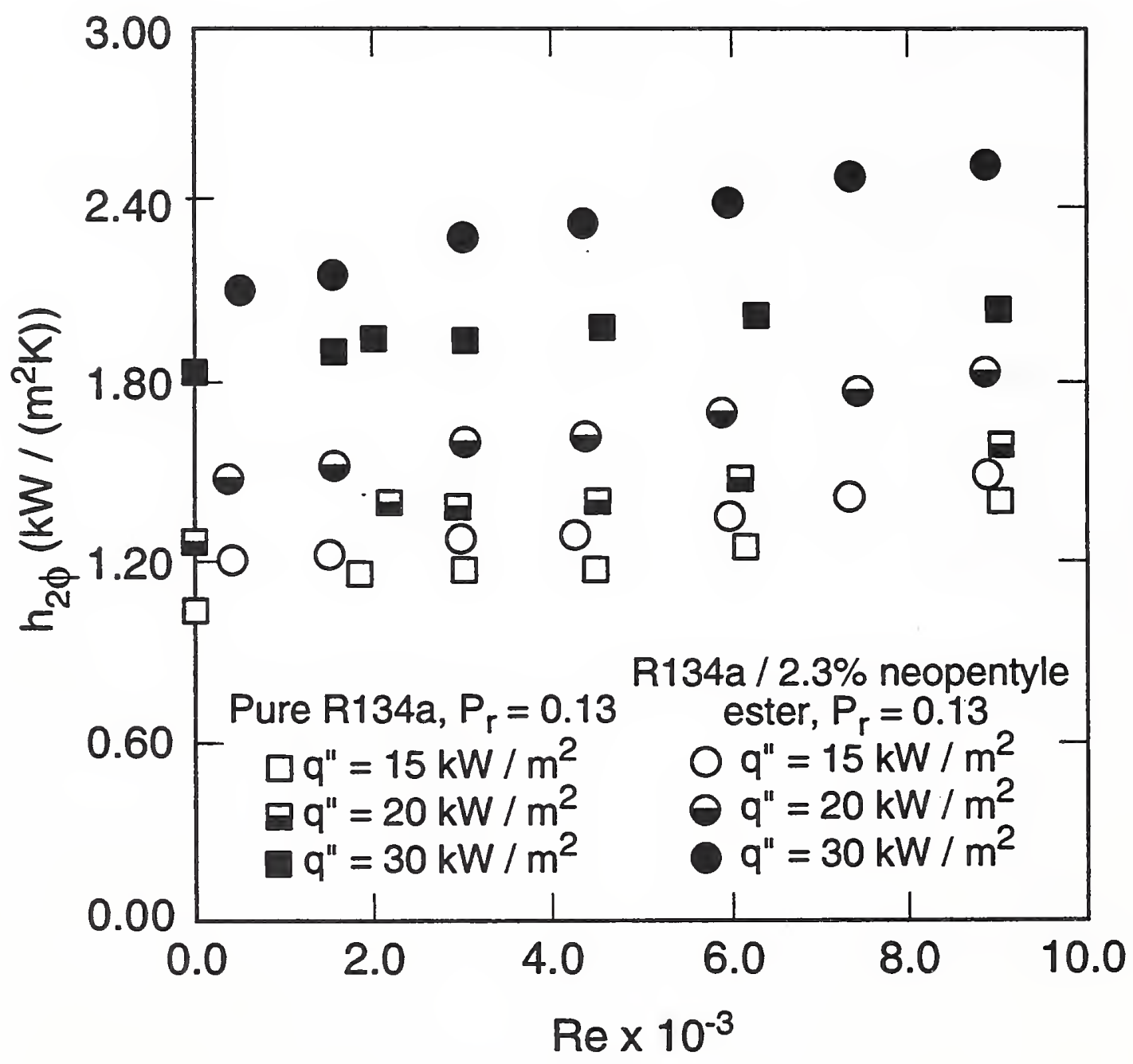

Fig. 6 Two-phase heat transfer coefficient measurements for R134a/2.3\% neopentyle polyol ester mixture and pure R134a at $\mathrm{P}_{\mathrm{r}}=0.13$ 


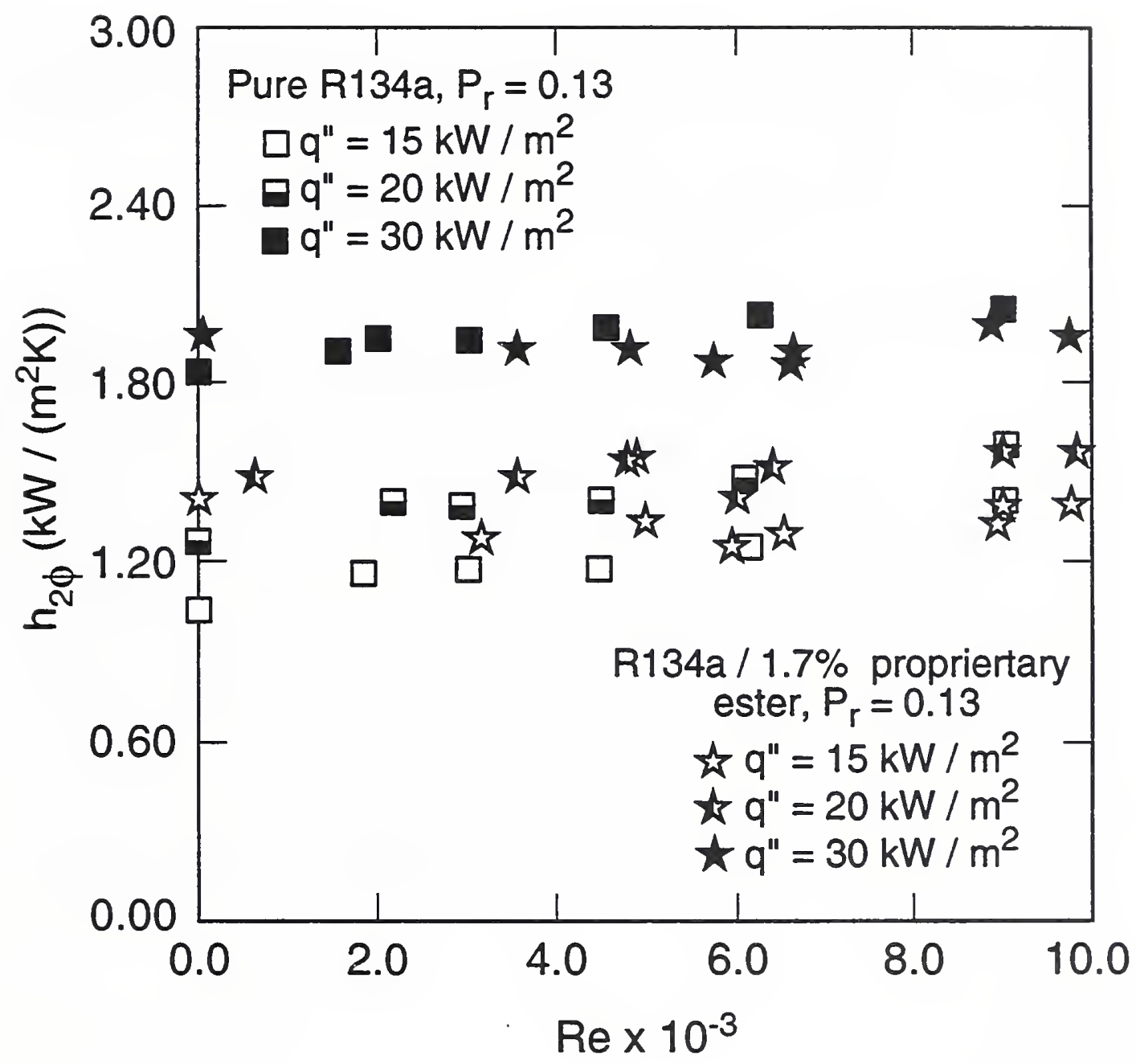

Fig. 7 Two-phase heat transfer coefficient measurements for $\mathrm{R} 134 \mathrm{a} / 1.7 \%$ polyol ester mixture and pure R134a at $P_{\mathrm{r}}=0.13$ 


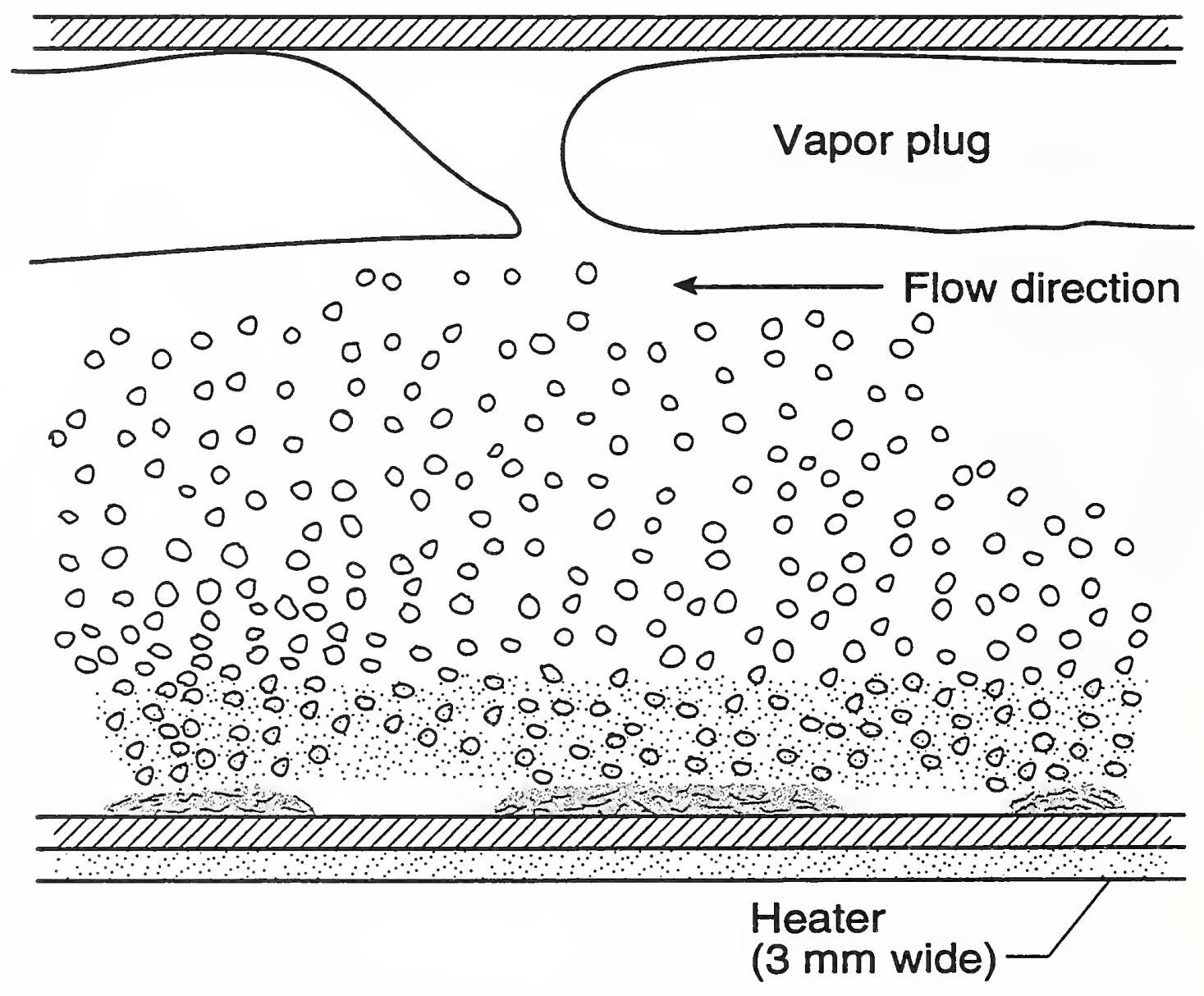

Fig. 8 Flow pattern for R134a/0.9\% neopentyle polyol ester lubricant nucleate flow boiling 


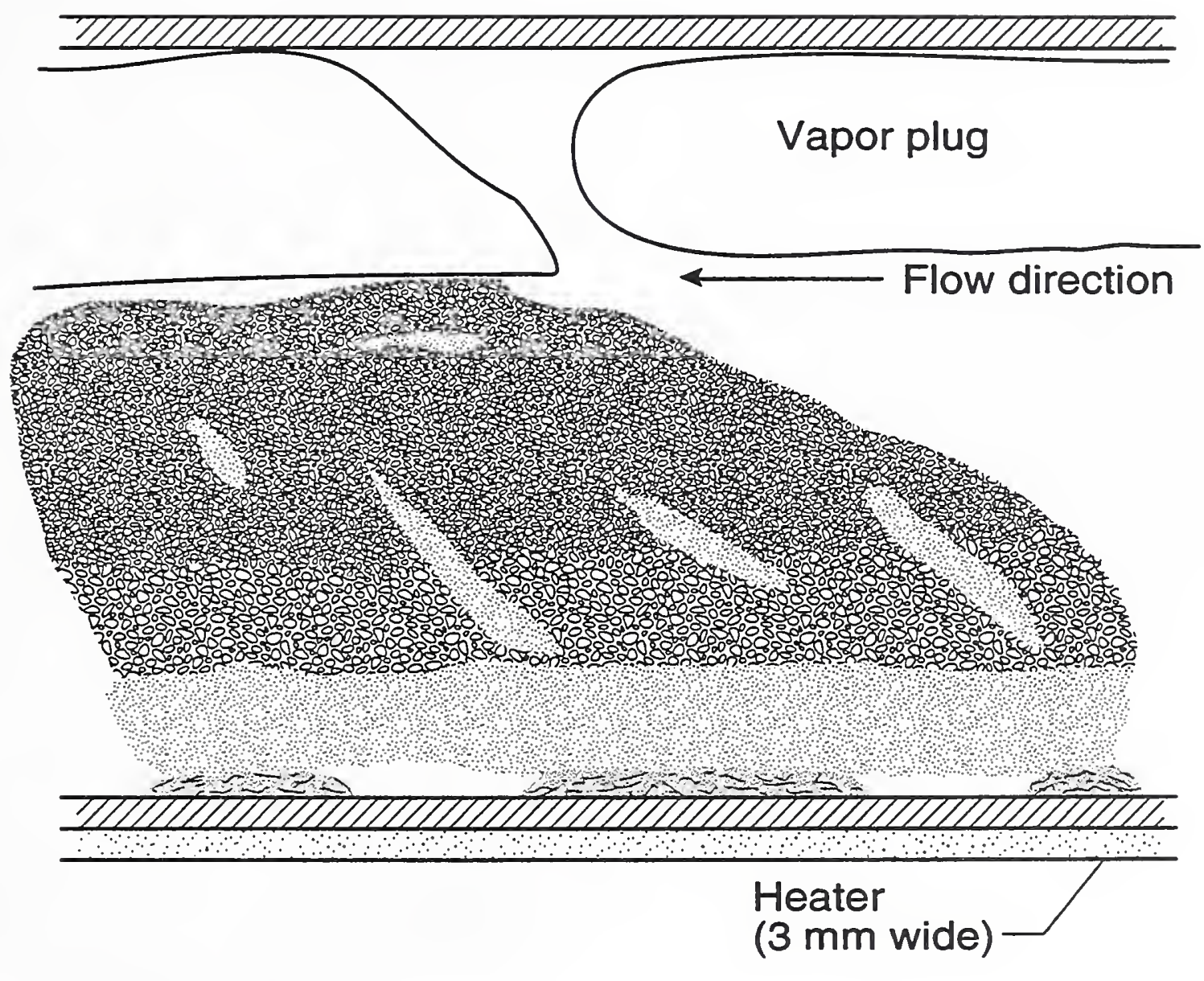

Fig. 9 Flow pattern for R134a/2.3\% neopentyle polyol ester lubricant nucleate flow boiling 


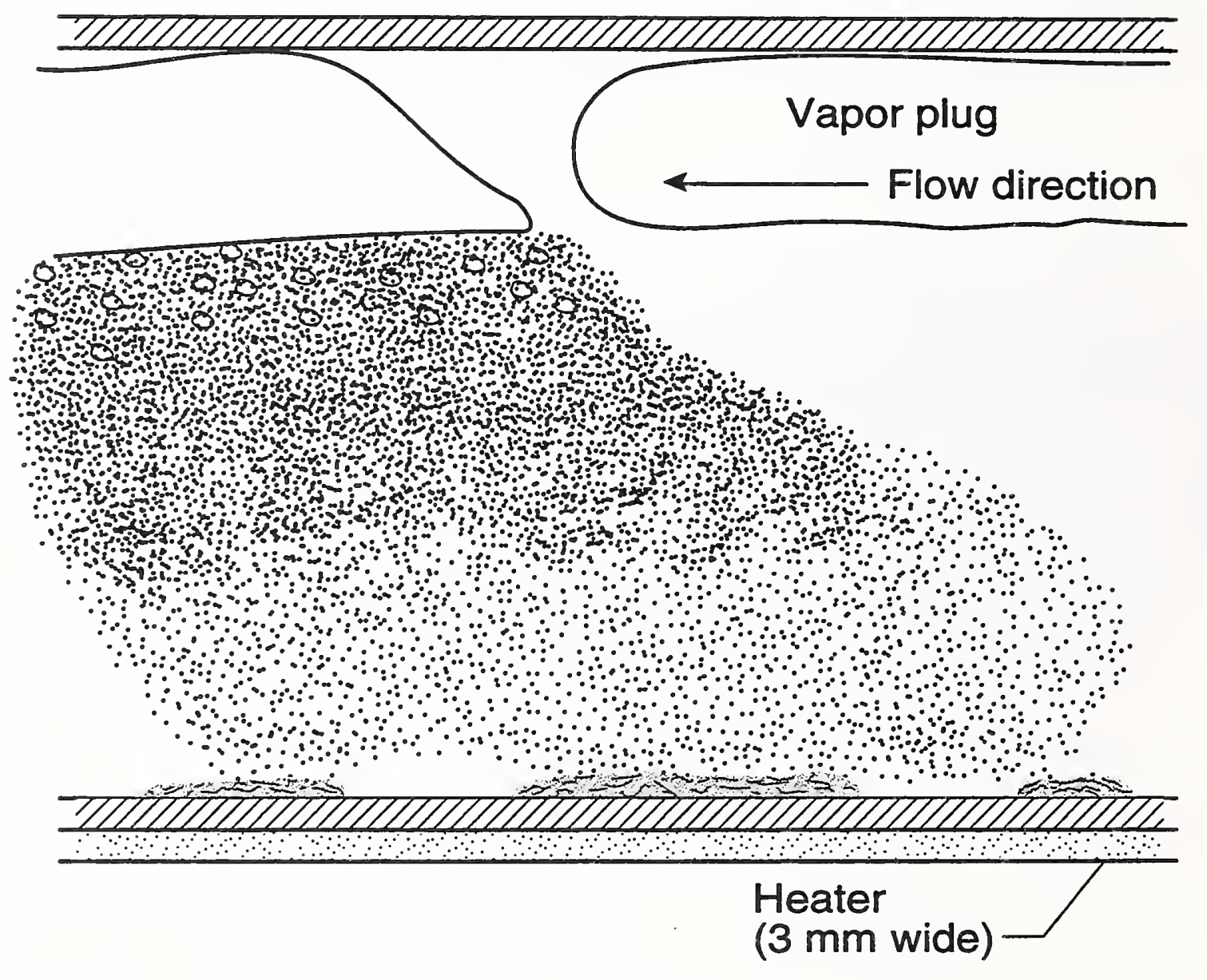

Fig. 10 Flow pattern for $\mathrm{R} 134 \mathrm{a} / 1.7 \%$ proprietary polyol ester lubricant nucleate flow boiling 

